\title{
Narrative Review: how long should patients with cough variant asthma or non-asthmatic eosinophilic bronchitis be treated?
}

\author{
Akio Niimi \\ Department of Respiratory Medicine, Allergy and Clinical Immunology, Nagoya City University, Nagoya, Japan \\ Correspondence to: Akio Niimi, MD, PhD. Department of Respiratory Medicine, Allergy and Clinical Immunology, Nagoya City University, Nagoya, \\ Japan. Email: a.niimi@med.nagoya-cu.ac.jp.
}

\begin{abstract}
The causes of chronic cough can be categorized into eosinophilic and noneosinophilic disorders, and approximately $30 \%$ to $50 \%$ of people with chronic cough have eosinophilic airway inflammation, the presence of which can be confirmed by sputum eosinophilia or elevated exhaled nitric-oxide levels. Cough variant asthma (CVA) is a phenotype of asthma which lacks wheezing or dyspnea, and consistently one of the most common causes of chronic cough worldwide. CVA and non-asthmatic eosinophilic bronchitis (NAEB) shares common feature such as chronic dry cough, eosinophilic inflammation, and development of chronic airflow obstruction (CAO) and asthma in a subset of patients. The distinctive characteristic of these conditions is the presence of airway hyperresponsiveness in CVA but not in NAEB. Coughing is responsive to bronchodilators such as beta-agonists in CVA, but such feature has not been clarified in NAEB. Inhaled corticosteroids (ICSs) are the first-line treatment, and leukotriene receptor antagonists are also effective, in patients with both CVA and NAEB. This review will give an outline of clinical and physiological features, and prognosis and its determinants of CVA and EBNA. Further, the rationale and evidence, despite limited, for the need of long-term treatment will be discussed. The development of airway remodeling due to mechanical stress to the airways exerted by long-standing coughing will also be discussed.
\end{abstract}

Keywords: Cough variant asthma (CVA); non-asthmatic eosinophilic bronchitis (NAEB); eosinophilic airway inflammation; airway remodeling; chronic cough; long-term treatment

Submitted May 24, 2020. Accepted for publication Feb 08, 2021.

doi: $10.21037 /$ jtd-20-2026

View this article at: http://dx.doi.org/10.21037/jtd-20-2026

\section{Introduction}

Chronic cough is a major clinical problem. The causes of chronic cough can be categorized into eosinophilic and noneosinophilic disorders (1), and approximately $30 \%$ to $50 \%$ of people with chronic cough have eosinophilic airway inflammation (2-4). Cough variant asthma (CVA) is characterized by eosinophilic inflammation of the whole lower airways (5). Further, non-asthmatic eosinophilic bronchitis (NAEB) $(6,7)$ and atopic cough (8) also present with chronic cough and involve eosinophilic inflammation. Patients with atopic cough rarely progress to asthma, or suffer from chronic airflow obstruction (CAO). Treatment of atopic cough could therefore be symptomatic and shortterm $(8,9)$. In contrast, long-term anti-inflammatory treatment with inhaled corticosteroids (ICSs) is considered essential and recommended by guidelines for patients with CVA (9), and this might also be the case with EB, because CAO (ascribed to airway remodeling) and classic asthma may develop in both conditions (1). In this review regarding CVA/NAEB, their clinical and physiological features, and rationale and evidence (despite limited) for the need of long-term treatment will be discussed. The development of airway remodeling due to mechanical stress to the airways exerted by long-standing coughing will also be discussed, because this may result in a vicious cycle of cough and remodeling, and imply the importance of control of coughing.

We present the following article/case in accordance with the Narrative Review Checklist (available at http://dx.doi. org/10.21037/jtd-20-2026). 


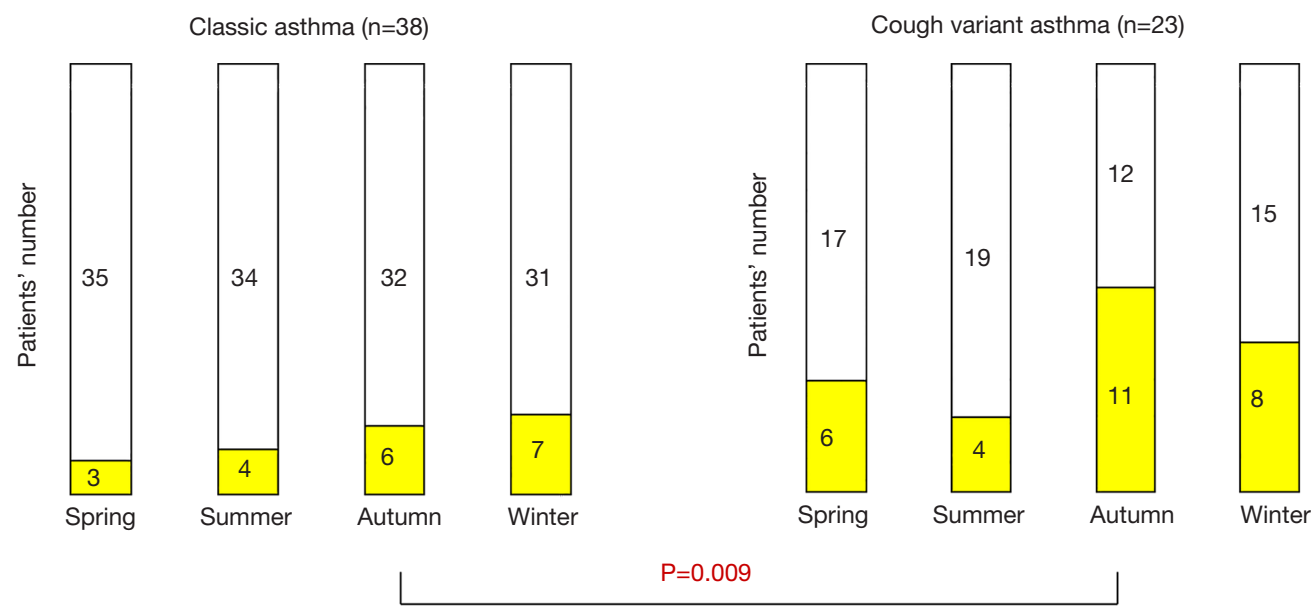

Seasonal exacerbations (+)

Seasonal exacerbation (-)

Figure 1 Prevalence of repeated seasonal exacerbations in each season in patients with classic asthma and CVA (16). A "seasonal" character of exacerbation was defined by at least one exacerbation in a specific season (spring, summer, autumn, and winter) repeatedly for least 2 years during the study period. Seasonal exacerbations as defined above was more common in CVA (18/23; 78\%) than in classic asthma (18/38; $47 \%)(\mathrm{P}=0.03)$, and CVA patients had seasonal exacerbations more frequently in autumn season than those with classic asthma (48\% vs. $16 \% ; \mathrm{P}=0.009)$.

\section{Clinical and physiological features and treatment of CVA}

CVA or asthma has consistently been one of the most common cause of chronic cough worldwide, together with GERD and upper airway cough syndrome. In Japan, CVA is the leading cause followed by GERD and sinobronchial syndrome (classic chronic rhinosinusitis and neutrophilic lower airway inflammation) (9-12), while one study from Poland showed a marked predominance of GERD followed by upper airway cough syndrome, probably indicating a regional or racial difference (13).

The prevalence of atopy in CVA, as defined by the presence of at least one positive serum specific IgE or skin test response to common aeroallergens, ranges from $40 \%$ to $80 \%(1,14,15)$, similarly to classic asthma. Interestingly, in a follow-up study of patients regularly visiting our clinic of Kyoto University for more than 2 years, repeated seasonal exacerbations in a specific season were more common in CVA $(18 / 23 ; 78 \%)$ than in classic asthma (18/38; 47\%) $(\mathrm{P}=0.03)$ (16). Patients with CVA had seasonal exacerbations more frequently $(48 \%)$ in autumn season than those with classic asthma (16\%) $(\mathrm{P}=0.009)$ (Figure 1). The latter phenomenon in CVA was associated with sensitization to housedust-mite (HDM) $(\mathrm{P}=0.004)(16)$.
Cough is usually dry in CVA, but $33 \%$ of patients complained of productive cough in one study (17). AHR has been considered an essential feature of CVA, but it is milder in CVA than in classic asthma in a majority of studies $(1,18)$. Peak expiratory flow (PEF) or $\mathrm{FEV}_{1}$ values are normal to near normal in most CVA patients, but may be significantly lower when compared with healthy subjects or patients with nonasthmatic cough (5). Mild diurnal change of PEF or its fluctuation in parallel with coughing may be observed, and cough is responsive to bronchodilators, suggesting that coughing of CVA results from bronchoconstriction based on airway inflammation and mild AHR. However, recent evidence strongly indicates an important involvement of heightened cough reflex sensitivity (CRS), commonly assessed by capsaicin inhalation (19).

Eosinophils are increased in sputum $(15,17)$, bronchoalveolar lavage (BAL) fluid (peripheral airways and lung parenchyma), and bronchial mucosa (5) (central airway) of patients with CVA, and the magnitude of increase correlates with severity of disease (5). The degree of mucosal and bronchoalveolar eosinophilia was similar between classical asthma and CVA, indicating a similarity in the site of inflammation (5), while increases of sputum eosinophils and exhaled nitric oxide (FeNO) levels in CVA are more modest as compared with classic asthma in 


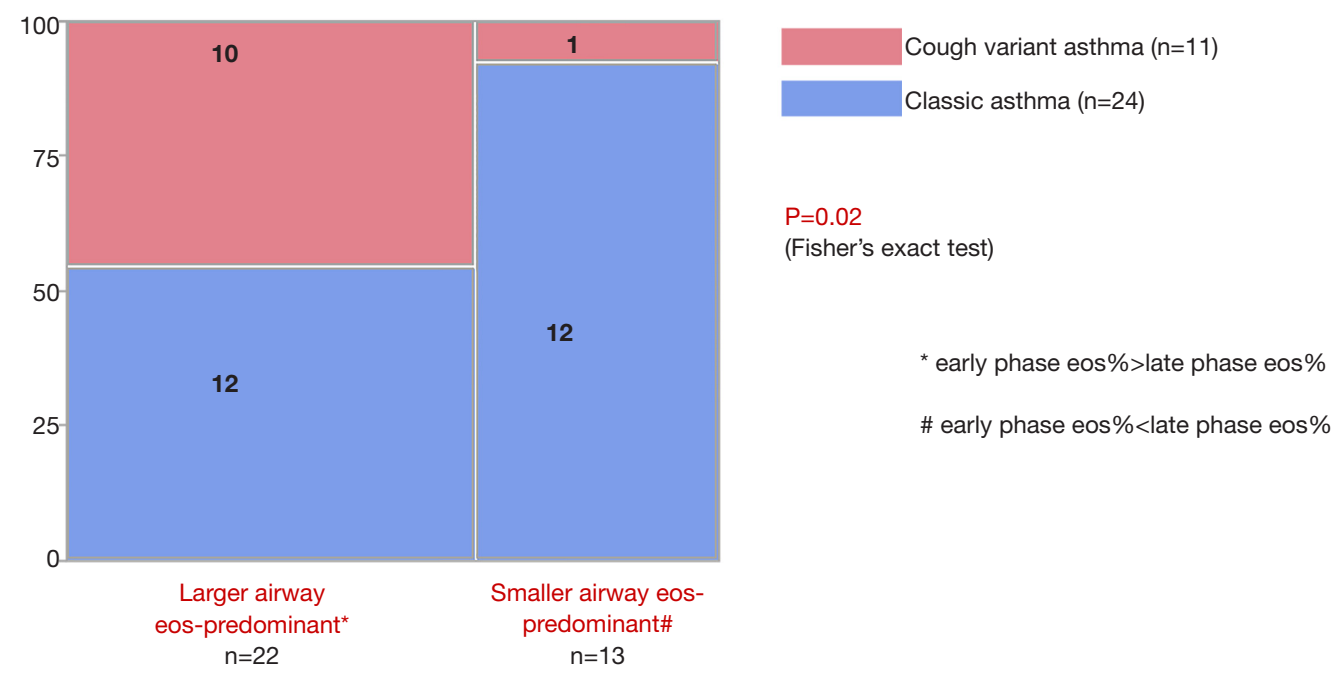

Figure 2 Prevalence of classic asthma and CVA patients in two novel phenotypes of asthma defined by the predominant cite of eosinophilic airway inflammation $(19,22)$. By using early-phase (first-half 15 minutes) and late-phase (second-half 15 minutes) induced sputum, patients were divided into "larger airway eosinophil-predominant group" (early-phase eos\% > late-phase eos\%) and "smaller airway eosinophilpredominant group" (early-phase eos\% < late-phase eos\%). Ten (91\%) of 11 CVA patients was categorized as larger airway eosinophilpredominant, while only half (12 of 24$)$ of classic asthma patients had smaller airway-predominant inflammation ( $\mathrm{P}=0.02)$. *eos: eosinophils.

many studies $(15,20)$. A recent meta-analysis consistently showed high specificity but low sensitivity of FeNO levels for the diagnosis of CVA (21). A preliminary study of 35 patients involving early- and late-phase induced sputum samples, however, has indicated that eosinophilic inflammation is predominant in the larger airways in CVA patients, as compared relatively with classic asthma patients (Figure 2) $(19,22)$. Indeed, McFadden described a group of asthmatics who predominantly complained of cough during exacerbations, and attributed their coughing to central airways obstruction by detailed physiological tests (23). One study has shown a similar pattern of sputum markers (cellular and humoral) between asthma and CVA (24).

Like in asthma, airway remodeling changes such as subepithelial basement membrane (SBM) thickening, goblet cell hyperplasia and vascular proliferation by mucosal biopsy, and airway wall thickening on CT images, have been demonstrated (25-27).

After the diagnosis is established, the mainstay treatment of CVA is ICS with an early introduction, as in classical asthma, essentially because of the presence of airway inflammation, and remodeling changes which are assumed secondary to chronic inflammation. The ACCP guidelines have made recommendations that the best therapeutic option for cough in asthma (and also NAEB) is
ICS followed by LTRAs (28). LTRAs also exert inhibitory effects on eosinophilic inflammation, and uniquely, on CRS $(19,29,30)$. The guidelines also presented limited evidence of antitussive effects (mostly assessed with subjective cough score) of beta-agonists, antihistamines, mast cell stabilizers such as nedocromil and cromolyn, and theophyllines (28). The standard combinations of ICSs/ long-acting beta-agonists (LABAs), the most potent bronchodilators, are widely used in asthma and CVA. They do exert antitussive effects, but unlikely to modulate CRS (19). Treatment options of CRS in asthma may include LTRAs, tiotropium, and bronchial thermoplasty despite very preliminary $(19,29-32)$.

It is very important to note that the presence of chronic cough $(33,34)$, increase of objective cough frequency (35), and heightened CRS to hypertonic saline/isocapnic hyperpnea (36) and capsaicin $(37,38)$ in individuals with asthma are all associated with poor control or prognosis and more severe disease phenotype (Figure 3) (38). The treatment strategy of cough or CRS is therefore essential in asthma, especially those with nonatopic disease $(31,37,38)$ and daytime coughing that is often refractory (39), despite night-time cough is characteristic of asthma (40). Eosinophils play important roles in the pathogenesis of cough of asthma (41), but ICSs 


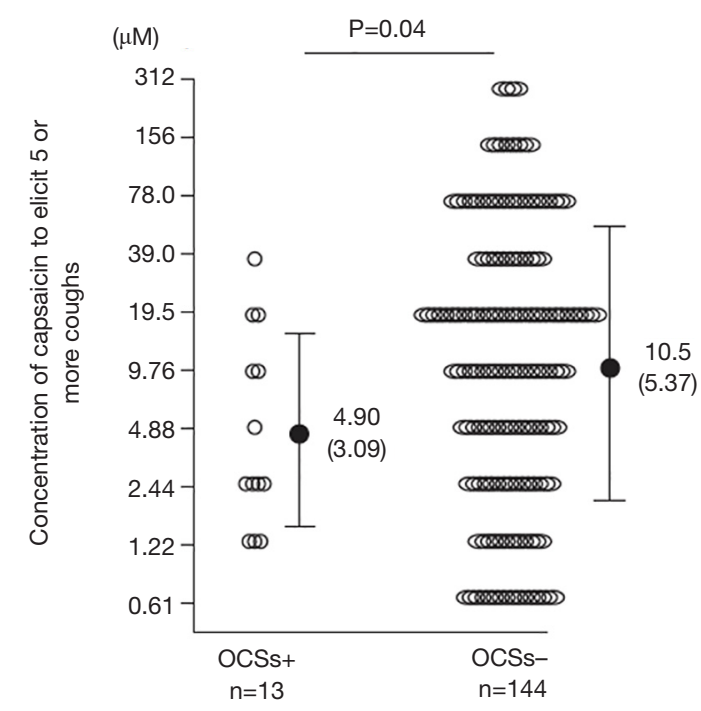

Figure 3 Cough receptor sensitivity (CRS) as define by the threshold concentration of capsaicin to elicit at least 5 coughs (C5) in patients with asthma stratified by severity, defined by the need of maintenance oral corticosteroids (OCSs) (38). Patients with more severe asthma showed significantly heightened CRS as compared with non-severe asthmatics. ${ }^{*} \mathrm{OCS} s+$, patients taking maintenance OCSs; OCSs-, patients not taking maintenance OCSs.

insufficiently attenuate cough and CRS of asthmatic subjects $(19,31,39,42)$. An anti-IL5 antibody mepolizumab, one of the most potent suppressor of eosinophilic inflammation, did not affect subjective cough of severe asthma patients, despite decrease of eosinophils and improved disease control (2). This fact is likely to be associated with refractoriness of asthmatic cough $(19,39,42)$. The updated ACCP guidelines suggest ICSs as first line treatment of asthmatic cough/CVA (28). If response is incomplete in CVA patients, or if cough is the remaining isolated symptom following ICSs treatment in patients with asthma in whom cough was one of their symptoms, the guidelines suggest stepping up the ICS dose and considering a therapeutic trial of an LTRA after reconsideration of alternative causes of cough. Beta-agonists could also be considered in combination with ICS (28). The reason why LTRAs, rather than beta-agonists, are recommended as the second-line treatment is not specified in the ACCP guidelines, but I personally think of the response to LTRAs, and the refractoriness to ICSs/LABAs, of CRS in asthma (19).

\section{Clinical and physiological features and treatment of NAEB}

NAEB [originally eosinophilic bronchitis without asthma (5)] is pathologically similar to, but is physiologically different from asthma in that it lacks AHR (1). It was not proposed as a distinct entity initially but aroused some controversy as to the relationship between eosinophilic airway inflammation and AHR (1). It is now considered an important cause of chronic cough, and a study by Brightling et al. involving sputum induction as a routine diagnostic tool has attributed $13 \%$ of chronic cough cases to NAEB (43). Cough was originally described as productive, but many patients have non-productive cough.

Prevalence of atopy in NAEB is approximately $20-70 \%$ from a literature review (1,44-48). Sporadic cases of workrelated NAEB have been reported (49). However, detailed profiles of sensitized allergens have not been reported, as have been in asthma and CVA $(14,15)$.

The methacholine $\mathrm{PC}_{20}-\mathrm{FEV}_{1}$ is within normal limits in most cases. CRS is increased but may normalize after ICS treatment in association with the attenuation of cough (50).

Sputum eosinophilia should be present in $100 \%$ of cases by the definition of disease. Metachromatic cells (mast cells or basophils) are increased in sputum and mucosal brushings as well $(6,44)$. The only pathological difference was that asthmatics showed an increase of mast cells infiltrating in ASM compared with other groups, which was associated with AHR (45). Mast cells were not increased in ASM of NAEB patients (45). These features may explain the presence or absence of AHR and airflow obstruction in asthma and NAEB (45). In contrast, mucosal and submucosal mast cells are increased in number in EBNA, as suggested by an increase of metachromatic cells in sputum and mucosal brushings $(6,44)$. Superficial mast cells, rather than those in ASM, may be relevant to cough of NAEB, possibly through release of tussive mediators such as histamine and prostaglandin D2 (51).

Endobronchial biopsies have revealed remodeling features such as subepithelial thickening and vascular proliferation, in addition to eosinophil infiltration in the epithelium and submucosa, and the degrees of which are similar to those in asthma (45-48). A CT study showed that airway wall thickness was significantly greater in asthmatics than in patients with NAEB and was similar in NAEB 
Table 1 Progression of CVA to classic asthma

\begin{tabular}{lccc}
\hline Author & $\mathrm{N}$ & Observation & Prevalence of progression \\
\hline Children & & & \\
$\quad$ Koh (2002) & 48 & 4 yrs & $21(43 \%)$ \\
Todokoro (2003) & 52 & $>3$ yrs & $28(54 \%)$ \\
Adults & & & \\
Nakajima (2005) & 28 & 5 yrs & $10 \%)$ \\
Fujimura (2003) (50) & 51 & 3.7 yrs & ICS-: $6 / 20(30 \%) ;$ \\
& & & ICS+: $2 / 31(6 \%)$ \\
\hline
\end{tabular}

CVA, cough variant asthma.

Table 2 Progression of CVA to classic asthma (56)

\begin{tabular}{|c|c|c|c|}
\hline 4-yr follow-up of 42 cases & \multicolumn{2}{|c|}{ Progressed? } & $\mathrm{P}$ \\
\hline Male/female & $6 / 7$ & $15 / 14$ & 0.99 \\
\hline Age (yrs) & $43 \pm 14$ & $42 \pm 15$ & 0.82 \\
\hline Disease duration (mo) & $33 \pm 63$ & $25 \pm 34$ & 0.26 \\
\hline Airway reactivity (SRrs) & $2.1 \pm 1.2$ & $1.7 \pm 1.0$ & 0.24 \\
\hline Use of ICS & $3(23 \%)$ & $17(59 \%)$ & 0.047 \\
\hline
\end{tabular}

CVA, cough variant asthma; ICS, inhaled corticosteroids.

patients and controls (52). Features of small airway disease (centrilobular prominence and air trapping) were similar in NAEB patients and asthmatics and were significantly greater than in controls. Central rather than small airways may thus contribute to AHR that occurs in asthmatics but not in patients with NAEB (45). However, the interpretation of these results may require caution, because smaller airways are generally considered more importantly involved in AHR than larger airways (53-55), while the reverse might be true for cough $(19,22,23,26,32)$.

Anti-inflammatory treatment with ICS or avoidance strategies, when the inflammation is due to an occupational exposure or inhaled allergen, are the mainstay therapies for the treatment of NAEB (1). Patients improve symptomatically and have a significant fall in their sputum eosinophil count following ICS treatment (50). Montelukast is also effective as an add-on to ICS, and equivalent to doubling of ICS with respect to cough VAS or LCQ (28). Capsaicin CRS, which was moderately increased at baseline, improved toward normal after ICS, and the treatment-induced changes in CRS and sputum eosinophils significantly correlated (50). These findings suggest contribution of heightened CRS and its causal relationship with eosinophilic inflammation in EB.

The ACCP guidelines suggest ICSs as first line treatment of adult and adolescent patients with chronic cough due to NAEB, and LTRAs as the second choice, as in CVA (28).

\section{Prognosis of CVA and its determinants}

\section{Asthma development: clinical features and medical intervention}

A subset of patients with CVA develop wheezing and progresses to classic asthma. If ICS is not introduced, the progression rate is $30 \%$ to $40 \%$ in adults $(56,57)$, and may be even higher in children (Table 1). In our 4-year retrospective study of 42 patients with CVA, classic asthma developed in 13 patients (31\%; Table 2), which was associated solely with nonuse of ICS by univariate (Table 2) and logistic regression analysis (odds ratio 0.12 , 
Table 3 Remission of CVA* and Associated factors (56)

\begin{tabular}{|c|c|c|c|}
\hline Parameters & Remission+ & Remission- & $P$ value \\
\hline Age (yrs) & $32.9(17.9)$ & $46.0(13.0)$ & 0.048 \\
\hline Gender (F/M) & $3 / 4$ & $14 / 14$ & $>0.999$ \\
\hline Atopic status (Y/N) & $6 / 1$ & $21 / 7$ & $>0.999$ \\
\hline Current smoking $(\mathrm{Y} / \mathrm{N})$ & $0 / 8$ & $1 / 27$ & $>0.999$ \\
\hline $\mathrm{FEV}_{1}(\%$ pred $)$ & $90.9(18.9)$ & $89.3(15.4)$ & 0.848 \\
\hline Dmin (unit) & $7.8(6.6)$ & $4.5(5.6)$ & 0.055 \\
\hline $\mathrm{SRrs}\left(\mathrm{cmH}_{2} \mathrm{O} / \mathrm{L} / \mathrm{s} / \mathrm{min}\right)$ & $1.5(1.1)$ & $2.0(1.1)$ & 0.186 \\
\hline Daily dose of ICS $(\mu \mathrm{g})$ & $933(462.0)$ & $760(372.0)$ & 0.453 \\
\hline
\end{tabular}

${ }^{*}$ Remission of CVA: cough subsiding for $>1$ yr without any medication. CVA, cough variant asthma; ICS, inhaled corticosteroids.

$\mathrm{P}=0.037)(56)$. The risk of progression to classic asthma may thus be reduced by early introduction of ICS, while no similar evidence exists for other medications including LTRAs.

Regarding remission of CVA, 7 (20\%) of 35 assessable patients from our series in Kyoto went into remission as defined by cough subsiding for $>1$ year without any medication (Table 3). Younger age and lower airway reactivity (SRrs), but not use of ICS, were marginally associated with remission by logistic regression analysis (56). In young children with CVA, the recurrence rate of cough was significantly reduced by the addition of montelukast to ICS (58).

\section{Astbma development: allergy features}

In a cross-sectional comparison of the characteristics of 115 classic asthma and 74 CVA patients, the two groups of asthmatics were sensitized to one or more allergens at a similar prevalence. However, patients with classic asthma had greater age, disease duration, smoking prevalence and airflow obstruction, and higher blood eosinophils, total IgE, numbers of sensitized allergens, and rates of sensitization to dog dander ( $24 \%$ vs. $3 \%, \mathrm{P}<0.0001)$, HDM ( $46 \%$ vs. $28 \%, \mathrm{P}=0.02)$, and moulds $(17 \%$ vs. $7 \%, \mathrm{P}=0.047)$ than did patients with CVA. No specific antigen of CVA with higher sensitization rate than classic asthma was found (14) (Table 4).
Forty CVA patients from this original cohort were prospectively observed for 2 years to determine whether CVA would progress to classic asthma despite ICS treatment. Asthma developed in six $(15 \%)$ patients with CVA [lower prevalence than older cohorts not treated with ICS $(56,57)$ ], who had lower $\mathrm{FEV}_{1}$, larger number of sensitized allergens and higher rates of sensitization to HDM and dog dander than the remainders without wheezing development (Table 5) (14).

Another cross-sectional study of a more recent larger cohort from the same laboratory (recruited from 2007 to 2009) showed very consistent results (Table 6) (15), confirming the importance of sensitization to HDM and animal (especially dog) dander, for the presentation as classic asthma rather than CVA.

As summarized in Table 7, factors that may predict the development of classical asthma include AHR (57), exaggerated maximal airway response to methacholine, sputum eosinophilia, allergen sensitization (14) and failure to use ICS $(56,57)$.

\section{Lung function decline}

Annual average changes of $\mathrm{FEV}_{1}$ were reportedly similar among patients with CVA $(-29 \mathrm{~mL})$, those with atopic cough $(-21 \mathrm{~mL})$ and healthy subjects $(-28 \mathrm{~mL})$. Values for CVA patients ranged from approximately $-90 \mathrm{~mL}$ to 
Table 4 Characteristics of cough variant asthma and asthma patients (14)

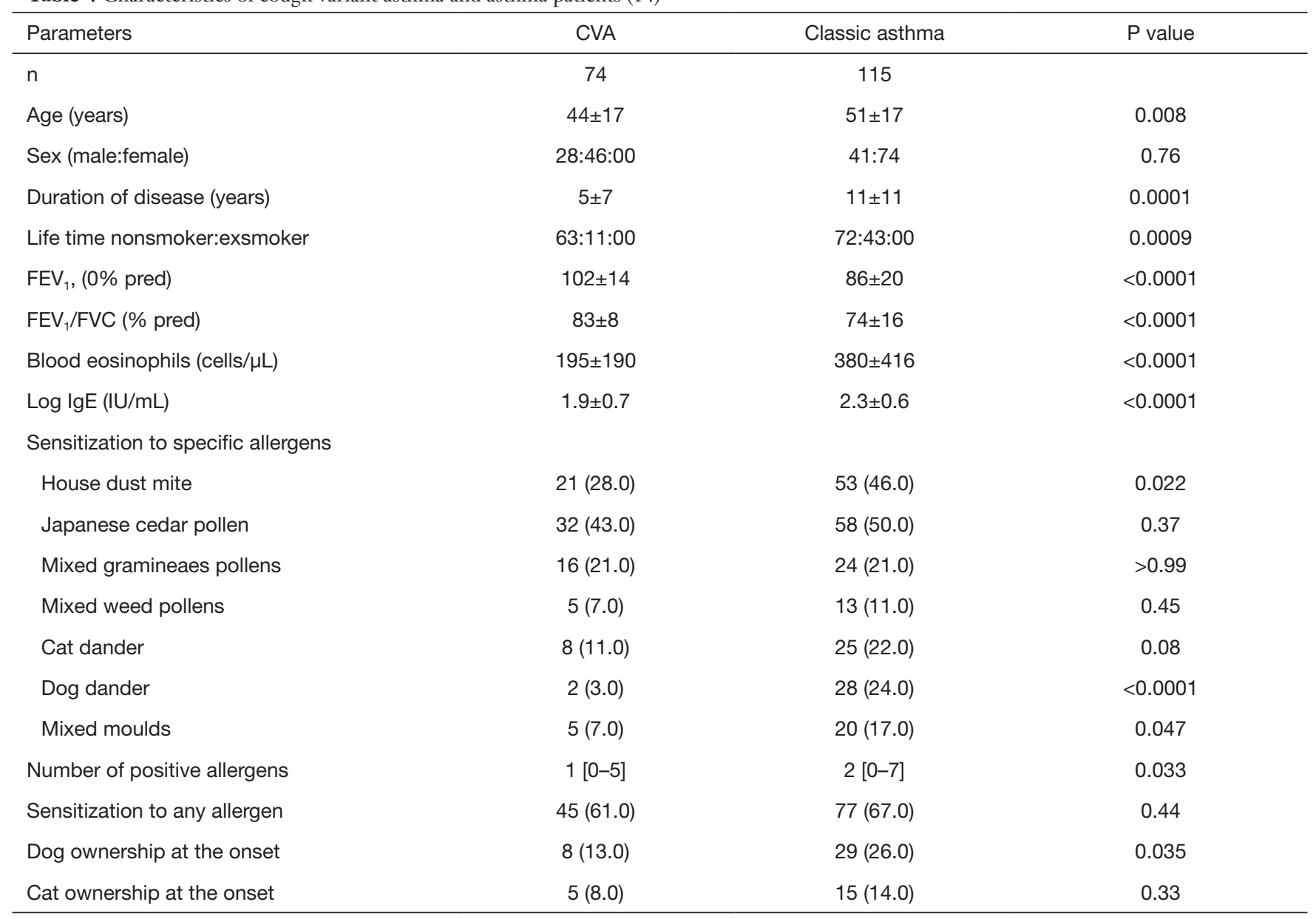

CVA, cough variant asthma.

$+30 \mathrm{~mL}$ (59). We retrospectively analyzed the annual $\mathrm{FEV}_{1}$ changes for 3 years in 11 patients with CVA (1). Patients were divided into two groups according to the cough severity during the 3 rd year of follow-up: mild and difficultto-control. The characteristics of two patient groups did not significantly differ at baseline, but at the end of follow-up, the difficult-to-control group was treated with higher doses of ICS than the mild group $(400 \pm 163$ vs. $143 \pm 140 \mathrm{mcd} /$ day of fluticasone equivalent, $\mathrm{P}=0.03)$, reflecting severity. During the follow-up period, 1 patient with mild CVA and 1 with difficult-to-control disease developed wheezing. The annual decline in $\mathrm{FEV}_{1}$ was steeper in the patients with difficult-to-control CVA $(62 \pm 35 \mathrm{~mL} /$ year $)$ than in those with mild disease $(2 \pm 36 \mathrm{~mL}, \mathrm{P}<0.01)(1)$. These results, are consistent with a study in asthma that showed a positive relationship between the frequency of exacerbations and annual decline of $\mathrm{FEV}_{1}(60)$.

\section{Inflammatory subtype and future maintenance therapy/ control}

In addition to eosinophils, neutrophils are also increased in airway mucosa of patients with refractory CVA (25). We investigated the characteristics of inflammatory subtypes in 98 CVA patients using induced sputum cell profiles defined by the cut-off levels of $61 \%$ for neutrophils and $1 \%$ for eosinophils (61). All patients underwent treatment with ICS ( $800 \mathrm{mcg}$ daily by average of budesonide or equivalent) with or without other controllers for 24 months, and the treatment was adjusted in a "real-life" fashion according to the physicians' decision. Daily ICS doses required to maintain control were consistently highest throughout follow-up in the mixed granulocytic subtype (both cells above cut-off) than in the other subtypes in this order: mixed granulocytic $>$ eosinophilic $>$ neutrophilic 
Table 5 Characteristics of CVA patients with and without development of wheezing: associated factors in 40 patients treated with ICS for 2 years (14)

\begin{tabular}{|c|c|c|c|}
\hline Parameters & Wheezing (-) & Wheezing $(+)$ & $P$ value \\
\hline $\mathrm{n}$ & 34 & 6 & \\
\hline Age (years) & $48 \pm 18$ & $35 \pm 13$ & 0.08 \\
\hline Sex (male:female) & $8: 26$ & 4:2 & 0.055 \\
\hline Duration of disease (years) & $5 \pm 6$ & $2 \pm 2$ & 0.20 \\
\hline Life time nonsmoker: ex-smoker & $30: 4$ & 4:2 & 0.21 \\
\hline $\mathrm{FEV}_{1}(\%$ pred $)$ & $105 \pm 16$ & $88 \pm 9$ & 0.006 \\
\hline $\mathrm{FEV}_{1} / \mathrm{FVC}(\%$ pred) & $83 \pm 8$ & $82 \pm 6$ & 0.76 \\
\hline Initial dose of inhaled corticosteroid ( $\mu \mathrm{g} /$ day) & $603 \pm 446$ & $467 \pm 301$ & 0.52 \\
\hline Final dose of inhaled corticosteroid ( $\mu \mathrm{g} /$ day) & $618 \pm 342$ & $633 \pm 512$ & 0.70 \\
\hline Blood eosinophils (cells/ $\mu \mathrm{L})$ & $234 \pm 287$ & $149 \pm 36$ & 0.61 \\
\hline Log IgE (IU/mL) & $0.7 \pm 0.1$ & $1.1 \pm 0.5$ & 0.099 \\
\hline Airway sensitivity (log Dmin) $(\mu \mathrm{g} / \mathrm{mL})$ & $0.5 \pm 0.7$ & $0.2 \pm 0.6$ & 0.26 \\
\hline Airway reactivity $(\mathrm{SRrs})\left(\mathrm{cmH}_{2} \mathrm{O} / \mathrm{L} / \mathrm{s} / \mathrm{min}\right)$ & $1.5 \pm 1.5$ & $2.3 \pm 1.4$ & 0.074 \\
\hline \multicolumn{4}{|l|}{ Sensitization to specific allergens } \\
\hline House dust mite & $8(24.0)$ & $5(83.0)$ & 0.01 \\
\hline Japanese cedar pollen & $12(35.0)$ & $4(67.0)$ & 0.20 \\
\hline Mixed gramineaes pollens & $8(24.0)$ & $1(17.0)$ & $>0.99$ \\
\hline Mixed weed pollens & $2(6.0)$ & $2(34.0)$ & 0.10 \\
\hline Cat dander & $4(12.0)$ & $2(34.0)$ & 0.21 \\
\hline Dog dander & $0(0.0)$ & $2(34.0)$ & 0.019 \\
\hline Mixed moulds & $3(9.0)$ & $1(17.0)$ & 0.49 \\
\hline Number of sensitized allergen & $1[0-4]$ & $3[0-5]$ & 0.020 \\
\hline Sensitization to any allergen & $19(56.0)$ & $6(100.0)$ & 0.07 \\
\hline Dog ownership during follow-up & $6(18.0)$ & $1(17.0)$ & $>0.99$ \\
\hline Cat ownership during follow-up & $3(9.0)$ & $1(17.0)$ & 0.49 \\
\hline
\end{tabular}

CVA, cough variant asthma; ICS, inhaled corticosteroids.

(either cells above cut-off) > paucigranulocytic (both cells below cut-off), while the starting doses were similar (Figure 4) (61). The ratio of patients in which ICS was discontinued at 24 months also differed significantly among the four subtypes, being significantly higher in the paucigranulocytic subtype than in the eosinophilic and mixed granulocytic subtypes (Figure 4). The control levels of disease differed significantly among the four subtypes at 18 months and were significantly worse in the mixed granulocytic subtype than in the paucigranulocytic subtype, despite significantly higher ICS doses in the former. The mixed granulocytic group showed higher sputum levels of IL-8 and neutrophil elastase than in the other three groups. In that group, neutrophils may be recruited and activated in the presence of eosinophils, as indicated by in vitro studies (62) and thus participate in the pathophysiology of CVA (61). Inflammatory subtype of sputum may thus predict prognosis, as reflected by future need of ICS, of individual patients. These results have been repeated and confirmed by a series of evidence from Severe Asthma Research Program (SARP) $(63,64)$. They consistently demonstrated that mixed granulocytic subtype is the most 
Table 6 Characteristics and specific IgE results of CVA and classic asthma patients, recruited from September 2007 to August 2009 (15)

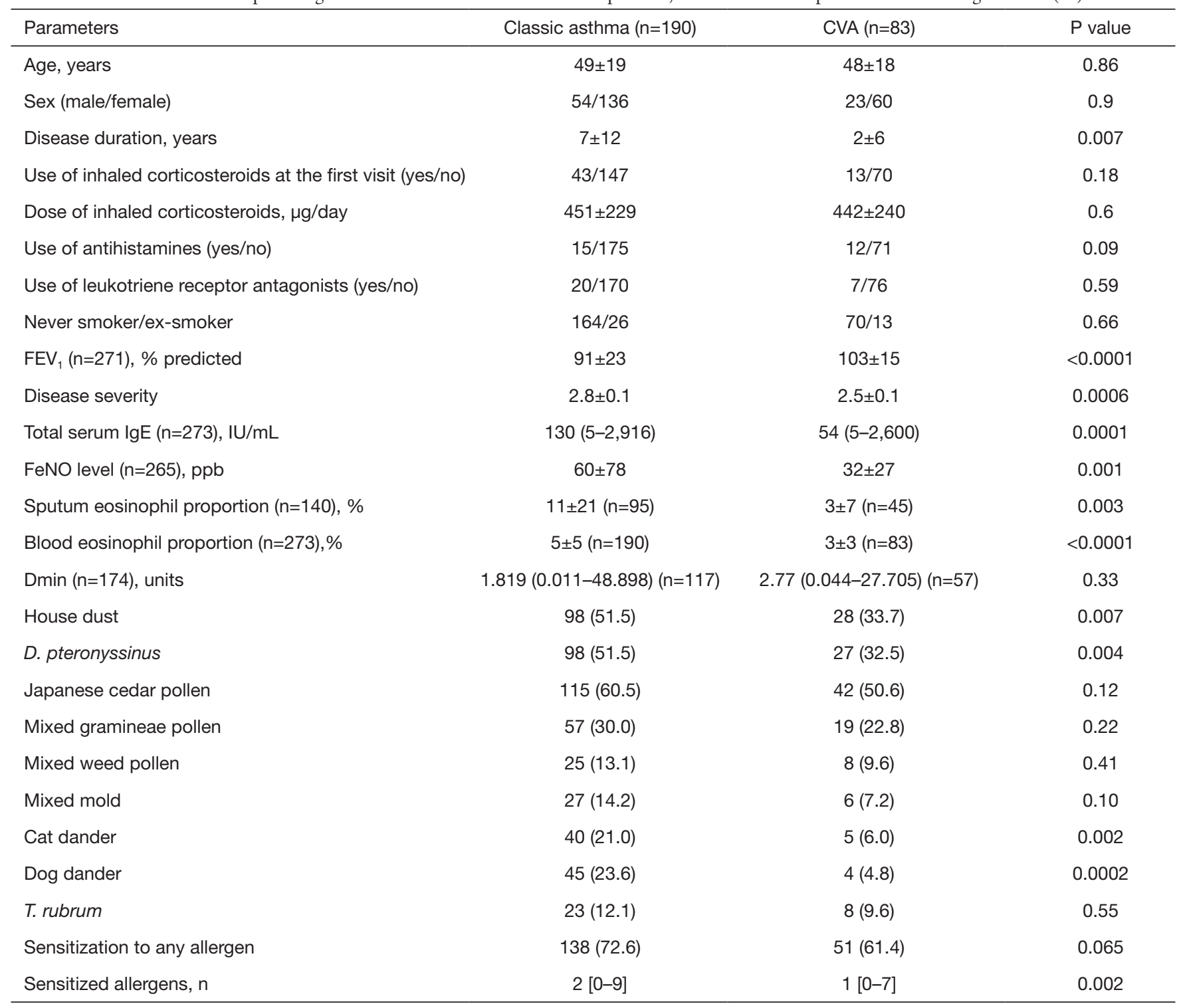

CVA, cough variant asthma.

refractory inflammatory subtype, characterized by the lowest lung function, worse asthma control, increased symptoms, greater healthcare requirements, and further loss in lung function, suggesting cell to cell interaction or overlapping inflammatory pathways $(63,64)$.

\section{Prognosis of NAEB and its determinants}

A single case report showed the development of irreversible airflow obstruction in a patient with NAEB (65). There are further four case studies regarding the prognosis of NAEB
(66-69), which will be presented in the chronological order. In a retrospective follow-up of the original 12 cases of Gibson $(6,70)$, three patients have been lost to followup and one has died from a pulmonary embolus, who had mild asthma at the time of death. None of the remaining 8 patients were being treated for EB or asthma. Cough had completely resolved in four patients, and four patients had persisting cough but due to other causes. Two of these patients had CAO, one being ascribed to a 60 pack-year smoking history. None of 6 patients available for examinations had developed AHR nor had sputum 
Table 7 Associated factors of progression of CVA to classic asthma (summary)

\begin{tabular}{|c|c|}
\hline \multicolumn{2}{|l|}{ Children } \\
\hline$\uparrow$ Sputum eosinophils & Kim et al. Clin Exp Allergy 2003 \\
\hline$\uparrow A H R$ (airway reactivity) & Koh et al. Allergy 2002 \\
\hline$\downarrow$ Age of onset & $\begin{array}{l}\text { Todokoro et al. Ann Asthma Allergy } \\
\text { Immunol } 2003\end{array}$ \\
\hline \multicolumn{2}{|l|}{ Adults } \\
\hline$\uparrow A H R$ (PC20-Mch) & Fujimura et al. Thorax 2003 (57) \\
\hline \multirow[t]{2}{*}{ Nonuse of ICS } & Fujimura et al. Thorax 2003 (57) \\
\hline & Matsumoto et al. J Asthma 2006 (56) \\
\hline$\uparrow A l l e r g e n$ sensitization & $\begin{array}{l}\text { Takemura et al. Clin Exp Allergy } \\
2007 \text { (14) }\end{array}$ \\
\hline$\downarrow \mathrm{FEV}_{1}$ & $\begin{array}{l}\text { Takemura et al. Clin Exp Allergy } \\
2007 \text { (14) }\end{array}$ \\
\hline$\uparrow$ Disease duration & Nakajima et al. Respiration 2005 \\
\hline
\end{tabular}

eosinophilia. The available data suggests that NAEB is generally a benign and self-limiting disorder (66).

Park et al. prospectively recruited 36 patients with NAEB to follow cough severity, $\mathrm{FEV}_{1}$, AHR, and sputum eosinophils for up to 48 months. ICS was stopped if cough subsided completely for 2 weeks. The cough disappeared in $27(75 \%)$ within 2 months after starting ICS, and in all within 4 months. Twelve patients were lost to follow within 4 months. Five (21\%) of the remaining 24 subjects had a recurrent episode of EB 4 to 6 months after disappearance of the first EB episode, who showed lower $\mathrm{FEV}_{1}$ at the 9 and 12 months of the study than in the 19 nonrecurrent patients $(\mathrm{P}<0.01)$. It was concluded that repeated episode of $\mathrm{EB}$ is associated with the development of CAO (67). These results are consistent with the evidence of CVA (1).

Berry et al. examined the longitudinal data of $>1$-year (average 3.1 years) of 32 patients with NAEB, for symptoms, eosinophilic airway inflammation, spirometry

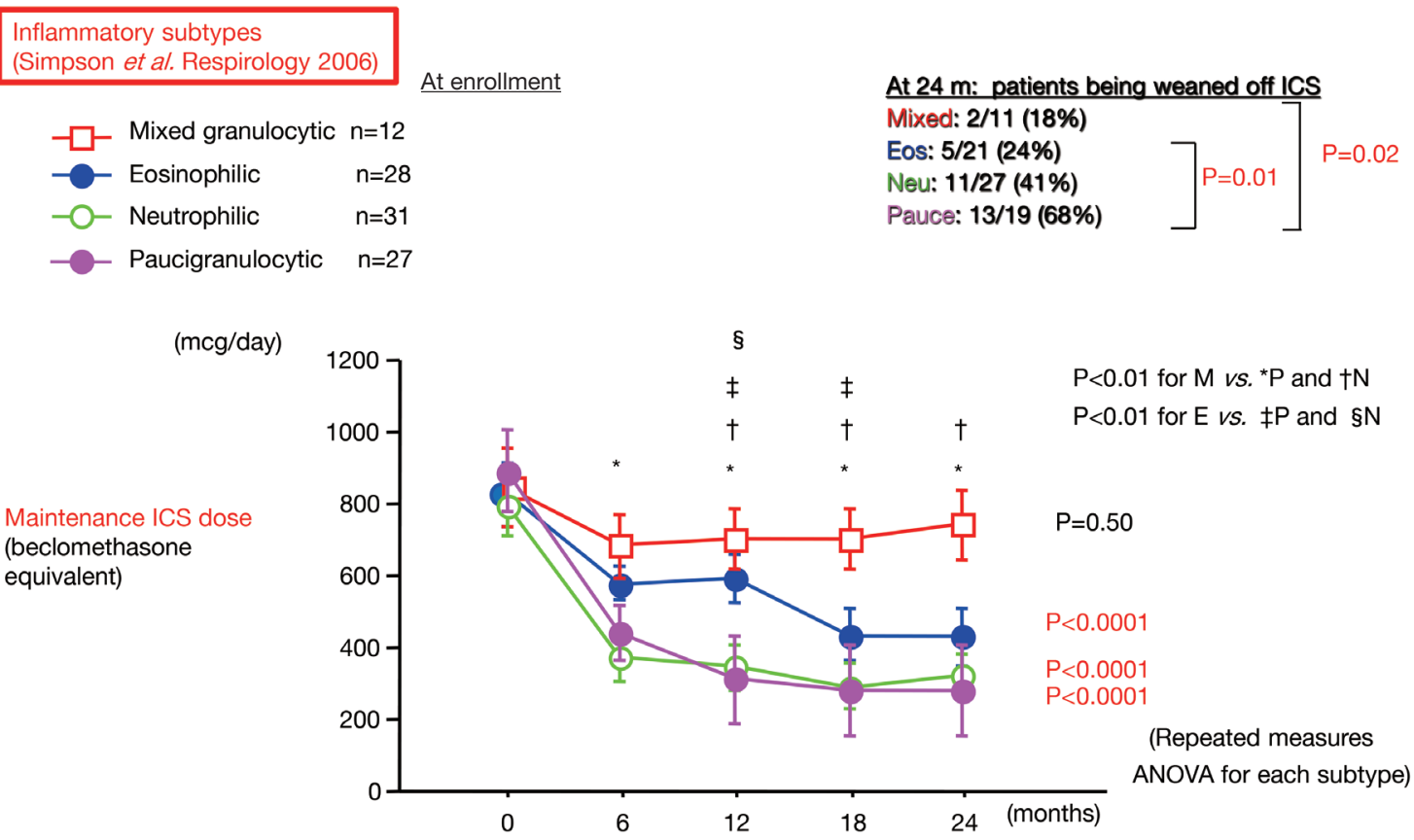

Figure 4 Maintenance ICS doses in CVA patients stratified by inflammatory subtype of sputum (61). ${ }^{*} \mathrm{CVA}$, cough variant asthma; ICS, inhaled corticosteroids. 
and AHR. Three patients developed asthma and AHR, and 5 developed CAO. Thirteen patients had ongoing cough and sputum eosinophilia ( $>3 \%$ ) on one or more occasions; 7 had ongoing otherwise unexplained cough without sputum eosinophilia (3 being smokers); 3 had no symptoms but sputum eosinophilia on one or more occasions; and only $1(3 \%)$ had complete resolution of symptoms and inflammation while off ICS. Multiple linear regression identified smoking, female gender and sputum eosinophilia over time, as the most important predictors of $\mathrm{CAO}$ (decline in $\mathrm{FEV}_{1}$ ) (68).

More recently, Lai and colleagues investigated longitudinal data of $>1$ year (median 4.1 years) in 141 patients with EB for symptoms, sputum eosinophil count, spirometry and AHR (69). All patients were treated with ICS (budesonide $400 \mathrm{mcg} /$ day) for at least 4 weeks and oral prednisone 10 to $15 \mathrm{mg} / \mathrm{d}$ in the initial 3 days. Cough relapsed in $59.6 \%$ after ICS treatment, whose risk factors were allergic rhinitis (OR, 4.37; 95\% CI, 1.05-18.20; $\mathrm{P}=0.043)$ and sputum eosinophilia at 4 weeks of ICS (OR, 9.49; 95\% CI, 2.38-37.85; $\mathrm{P}=0.001$ ). Mild asthma developed in eight patients $(5.7 \%)$. Only the relapse group showed an MMEF decline at the end of follow-up $(\mathrm{P}<0.05)$, while no progressive decline in $\mathrm{FVC}$ or $\mathrm{FEV}_{1}$ were observed. It was concluded that more than $50 \%$ of patients with NAEB have repeated episodes, which were associated with persistent sputum eosinophilia after treatment and allergic rhinitis (69).

In line with these results, a prospective observation of 89 unselected subjects with chronic cough for five years revealed that continuing regular cough was present in 31 (46\%) of the subjects, which was associated with presence of chronic rhinitis or esophageal reflux disease, baseline mild AHR to histamine, and baseline strong CRS to hypertonic saline (71). Further, the presence of allergic rhinitis was associated with more intense airway inflammation in CVA patients, as well as classic asthmatics (15). GERD symptoms are also associated with impaired cough-specific QoL in CVA patients (72). Allergic rhinitis and GERD may be associated with cough persistence and more intractable CVA and NAEB, probably contributing as comorbid cause(s) of cough.

\section{Cough and airway remodeling: a possible link}

Remodeling or structural changes of the airways have been considered characteristic features of asthma. They have been attributed mainly to chronic inflammation with eosinophil infiltration which produce transforming growth factorbeta, platelet-derived growth factor, cysteinyl leukotrienes (cys-LTs) etc. The presence of remodeling features, and resultant CAO, in CVA and NAEB is reasonable because they commonly share eosinophilic inflammation. However, various features of airway remodeling i.e., SBM thickening, vascular proliferation, epithelial shedding, goblet cell hyperplasia, increase of ASM and airway wall thickening on CT is also present in patients with non-asthmatic (i.e., noneosinophilic) chronic cough $(25,27,73,74)$. Patients with unexplained chronic cough may develop CAO (75). Mast cells may be involved in these changes since they are sources of various growth factors as well as tussive mediators (e.g., histamine, prostaglandin $\mathrm{D}_{2}$, and cys-LTs) $(25,30,41,51)$. Also, because bronchoconstriction without airway inflammation induced by repeated methacholine challenge elicits airway remodeling in clinical asthma (76), remodeling changes in chronic cough patients (either eosinophilic or not) may also be a consequence of longterm mechanical stimulation by coughing (74). Increase of goblet cells, epithelial shedding and airway wall thickness correlate with capsaicin CRS, indicating that remodeling may actively play roles in cough pathophysiology $(25,27)$. A guinea pig model of airway collapse that mimics cough induced by rapid negative pressure applied to the airway of artificially ventilated animals indicated that cough is a traumatic mechanical stress to the airway wall that induces neutrophilic airway inflammation and cough hypersensitivity (77). Cough stress to the airway wall may result in a self-perpetuating cough reflex cycle (77).

We aimed to investigate whether repeated cough itself induces airway remodeling and heightened CRS by using conscious guinea pigs in vivo $(78,79)$. Cough was induced by repeated exposure to $0.5 \mathrm{M}$ citric acid (CA) thrice weekly for 3 weeks (CA group), which is unlikely to induce tachyphylaxis. We set two control groups: one given saline (SA group), and the other given CA with pretreatment with an antitussive dextromethorphan according to the same protocol as CA group (CA+DEX group). Average cough number for $10 \mathrm{CA}$ exposures was evaluated as "cough index" in the CA group, which was divided into frequent cough (cough index $>5$ : CA-F) and infrequent cough $(<5$ : CA-I) subgroups for BAL and pathology analysis of day 25. The number of coughs significantly increased in the CA group (CA-F and CA-I combined) from day 13 onwards, but not in the SA or CA + DEX groups. Among various histologic changes, ASM area of small airways was significantly greater in the CA-F subgroup than in the other three groups (in 

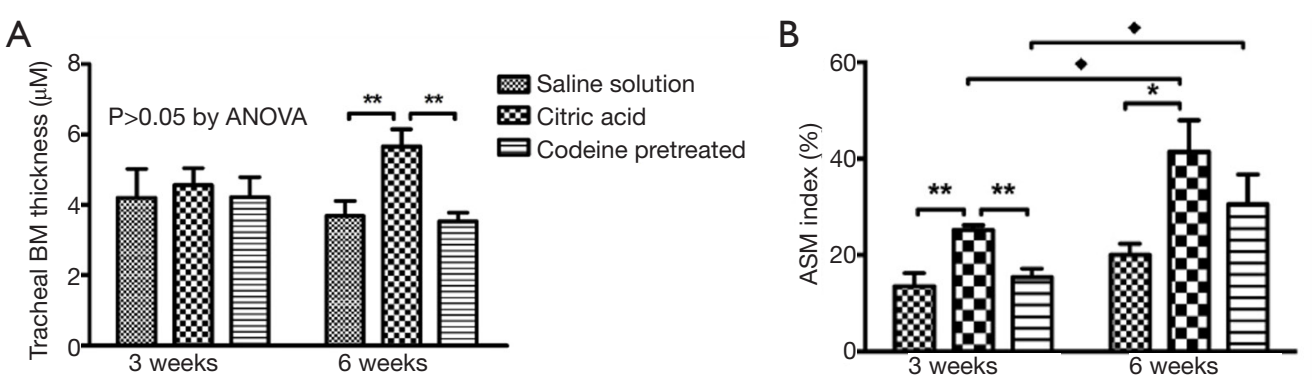

Figure 5 Histologic changes in (A) the BM thickness of tracheal and (B) the ASM index of small airways, in the three treatment groups of guinea pigs (saline, citric acid, and citric acid pretreated with codeine) after 3 weeks and 6 weeks $(79)$. ${ }^{* *} \mathrm{P}<0.01,{ }^{*} \mathrm{P}<0.05$ by one-way ANOVA, LSD post hoc test; $\diamond \mathrm{P}<0.05$ by Student's $t$-test. BM, basement membrane; ASM, airway smooth muscle.
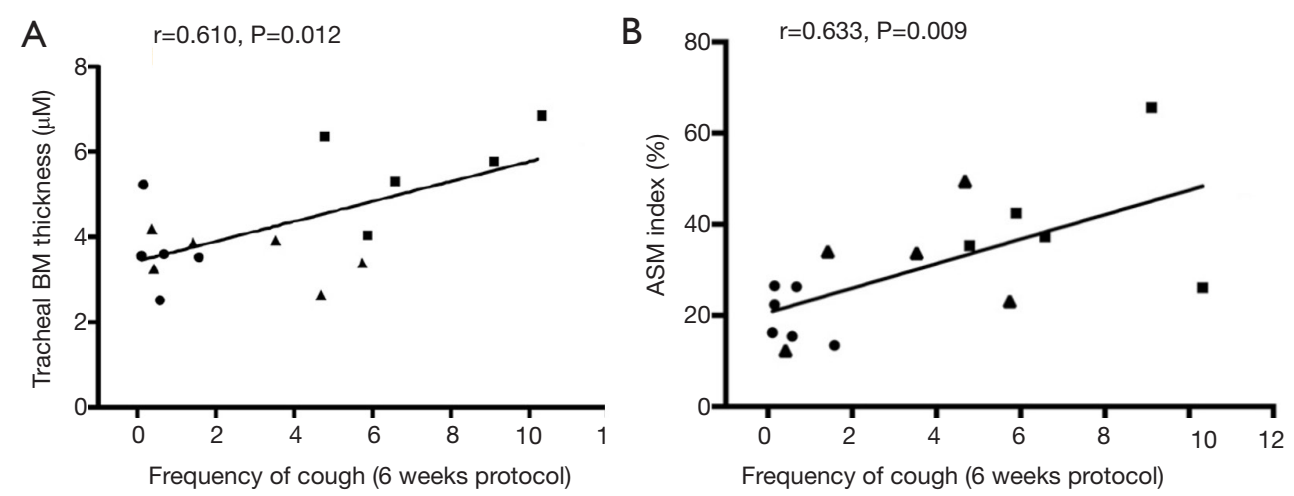

Figure 6 Correlation between the frequency of cough and (A) the tracheal BM thickness and (B) the ASM index of small airways after 6 weeks of CA exposure in guinea pigs (79). BM, basement membrane; ASM, airway smooth muscle; CA, citric acid.

which it was similar), and correlated with cough index in CA group (CA-F and CA-I combined; $r=0.77, \mathrm{P}=0.0002$ ). BAL cell profiles were similar among the four groups. We concluded that repeated cough induces ASM remodeling in the absence of inflammation. It was associated with heightened CRS, leading to a positive feedback mechanism for cough persistence (78).

In a subsequent study, we further investigated the airway pathology in prolonged cough models of guinea pigs (79). Animals were assigned to three treatment groups: CA alone, CA with codeine pretreatment, or SA. Animals were challenged with CA or SA solution thrice weekly. The intervention period was 22 or 43 days. Animals were challenged with CA on the first and last days of exposure. Lung specimens were obtained for pathologic analysis $72 \mathrm{~h}$ after the last exposure (Figure 5). The CA group had increased frequency of cough on both 22 and 43 days of exposure, compared with the other two groups. Tracheal SBM thickness was increased after 43 days of exposure
(Figure 5A), correlating with the frequency of induced cough (Figure 6A). The area of ASM in small airways increased in the CA group after both 22 and 43 days of exposure (Figure 5B), compared with the SA group. The increase of ASM at 43 days correlated with the frequency of induced cough (Figure 6B). As compared with the codeine group, the ASM area in small airways increased in the CA group after 22 days of exposure instead of 43 days of exposure. Goblet cell area, epithelial thickness, or number of neutrophils or eosinophils were unchanged. In conclusion, an increase in peripheral ASM area by repeated cough was confirmed. Moreover, tracheal SBM thickness increased by a prolonged exposure (Figure 7). Repeated cough may lead to airway remodeling, which was also associated with an increase of cough (79).

These pathological findings were strikingly consistent with a post-mortem pathological observation in humans, involving cases of asthma with $(n=51)$ or without $(n=29)$ granulocytic inflammation, and control subjects without 


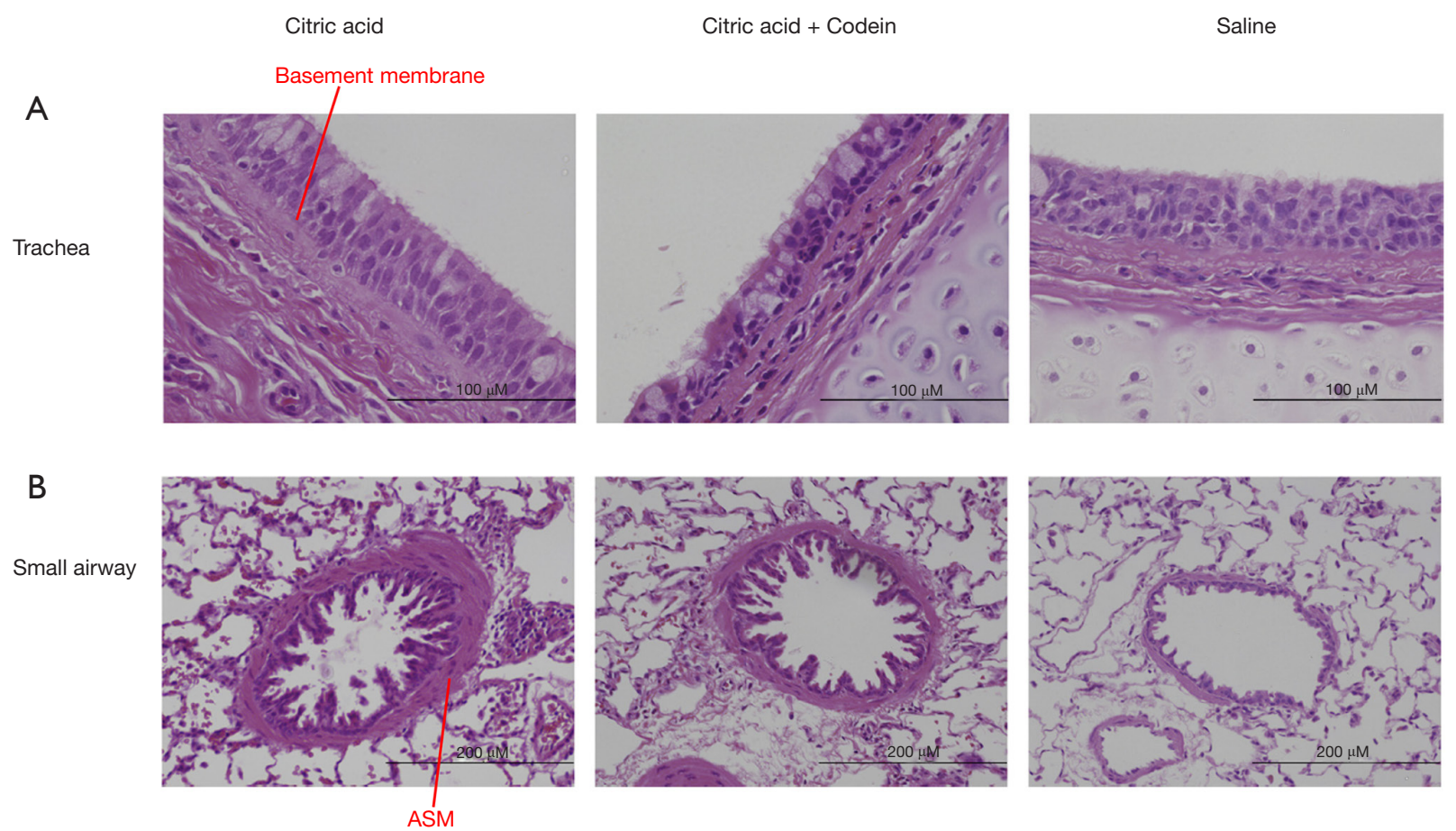

Figure 7 Representative photomicrographs of airway sections in the three treatment groups after 6 weeks of exposure (79). (A) In the large airways, BM thickness is increased after 6 weeks of treatment in the CA group compared with the other two groups. (B) In the small airways, ASM is increased after 6 weeks in the CA group compared with the other two groups. (hematoxylin and eosin, $\times 400$ ). CA, citric acid; SA, saline solution; COD, citric acid with codeine pretreatment; BM, basement membrane; ASM, airway smooth muscle.

asthma $(n=48)(80)$. The former two groups were defined according to the cutoff values of 5 cells $/ \mathrm{mm}^{2}$ for mean area densities of granulocytes within the inner airway wall of large and small airways. Thickening of the ASM layer and BM were the only findings of remodeling in asthmatics who lacked granulocytic cellular inflammation (80). These features were very similar to our guinea pig cough model $(78,79)$. In contrast, there were also increased inner and outer airway wall and mucus gland thickness, and narrowing of airway lumen due to ASM shortening and mucus obstruction in patients with granulocytic inflammation, compared with control subjects (80).

Irrespective of the details of airway pathology, symptombased control of coughing may simply be important from a standpoint of prevention of airway remodeling, which might result in cough hypersensitivity and vicious cycle of cough persistence $(74,81)$, as well as lung function impairment.

\section{How long should CVA/NAEB patients be treated?}

$\mathrm{CAO}$ and classic asthma thus may develop in CVA, and also in NAEB, although less prevalently.

Cough can subside promptly with ICS or ICS/LABA in the majority of CVA patients. Step down of treatment can then be considered, but cessation of treatment often results in relapse (56). Persistently symptomatic patients require long-term treatment, whose adherence to treatment will consequently be good. Contrary, prompt responders to ICS or ICS/LABA are apt to be noncompliant to treatment. However, no evidence exists as to how long should treatment be continued in such patients, and the ACCP guidelines do not mention the duration of treatment for CVA of NAEB (28). Long-term treatment based on objective monitoring, as recommended for asthma (e.g., lung function and $\mathrm{FeNO}$ ), is preferable, but such tests may not be available in the "real-world" settings.

The Japanese guidelines of cough management therefore suggested a practical management strategy of CVA, considering availability for general practitioners or nonspecialist settings (Table 8) (9). They classified CVA patients into those with seasonality of coughing, and those with perennial disease or recent onset, and showed different 
Table 8 Recommendation of how long should well-controlled CVA patients be treated (9)

(I) CVA patients with seasonality of coughing

Patients with intermittent seasonal disease who are otherwise asymptomatic between the active season may be treated only during the expected season, according to an international asthma guideline (82)

Such patients, however, may progress to perennial disease

(II) CVA patients with perennial disease, or whose seasonality is unknown because of recent onset

Symptoms should be reassessed every 2 to 3 months, and stepdown of treatment, if asymptomatic or almost asymptomatic, is considered, finally to the lowest dose of ICS alone. Then treatment may be stopped if asymptomatic after at least 1 to 2 years of ICS

However, possibility of relapse should be informed, and careful observation is required

CVA, cough variant asthma.

Table 9 Characteristics of CVA/NAEB patients who may be considered for longer-term treatment

- Initial nonuse of ICS

- Persistent sputum eosinophilia or elevated FeNO

- Mixed granulocytic inflammation (with eosinophils and neutrophils)

- Marked AHR

- Marked CRS

- Airflow obstruction

- Ongoing smoking

- More "severe" or "intractable" disease

- Comorbid allergic rhinitis

- More allergic patients especially if

$\diamond$ Sensitized to HDM, or dog dander

$\diamond$ continuously exposed to sensitized allergens

CVA, cough variant asthma; NAEB, non-asthmatic eosinophilic bronchitis; ICS, inhaled corticosteroids; CRS, cough reflex sensitivity.

strategy for each subtype (Table 8) (9).

It has not been clearly stated as to whether therapy for NAEB should be discontinued when symptoms resolve (28), but the treatment strategy may be similar to CVA. A recent open label, randomized, parallel-group study indicated that ICSs should be administrated for at least 2 months to reduce the relapse of NAEB (83).

\section{Conclusions}

Clinical and physiological features, and rationale and evidence for the need of long-term treatment of CVA/
NAEB was discussed, including the author's personal view. Although it is difficult to draw definite conclusions for the provided question of "how long treatment", the author would like to present characteristics of patients who have risk factors of relapse and/or chronic airflow obstruction/remodeling, and development of classic asthma, are therefore to be considered for longer-term treatment (Table 9).

\section{Acknowledgments}

Funding: None.

\section{Footnote}

Provenance and Peer Review: This article was commissioned by Prof. kefang Lai for the series "3rd International Cough Conference" published in Fournal of Thoracic Disease. The article was sent for external peer review.

Reporting Checklist: The authors have completed the Narrative Review Checklist. Available at http://dx.doi. org/10.21037/jtd-20-2026

Conflicts of Interest: All authors have completed the ICMJE uniform disclosure form (Available at http://dx.doi. org/10.21037/jtd-20-2026). The series "3rd International Cough Conference" was commissioned by the editorial office without any funding or sponsorship. Prof. Niimi serves as an editorial board member of Journal of Thoracic Disease. The authors have no other conflicts of interest to declare.

Ethical Statement: The authors are accountable for all aspects of the work in ensuring that questions related 
to the accuracy or integrity of any part of the work are appropriately investigated and resolved.

Open Access Statement: This is an Open Access article distributed in accordance with the Creative Commons Attribution-NonCommercial-NoDerivs 4.0 International License (CC BY-NC-ND 4.0), which permits the noncommercial replication and distribution of the article with the strict proviso that no changes or edits are made and the original work is properly cited (including links to both the formal publication through the relevant DOI and the license). See: https://creativecommons.org/licenses/by-nc-nd/4.0/.

\section{References}

1. Niimi A, Matsumoto H, Mishima M. Eosinophilic airway disorders associated with chronic cough. Pulm Pharmacol Ther 2009;22:114-20.

2. Diver S, Russell RJ, Brightling CE. Cough and Eosinophilia. J Allergy Clin Immunol Pract 2019;7:1740-7.

3. Carney IK, Gibson PG, Murree-Allen K, et al. A systematic evaluation of mechanisms in chronic cough. Am J Respir Crit Care Med 1997;156:211-6.

4. Gibson PG, Fujimura M, Niimi A. Eosinophilic bronchitis: clinical manifestations and implications for treatment. Thorax 2002;57:178-82.

5. Niimi A, Amitani R, Suzuki K, et al. Eosinophilic inflammation in cough variant asthma. Eur Respir J 1998;11:1064-9.

6. Gibson PG, Dolovich J, Denburg J, et al. Chronic cough: eosinophilic bronchitis without asthma. Lancet 1989;1:1346-8.

7. Brightling CE, Ward R, Goh KL, et al. Eosinophilic bronchitis is an important cause of chronic cough. Am J Respir Crit Care Med 1999;160:406-10.

8. Fujimura M, Ogawa H, Yasui M, et al. Eosinophilic tracheobronchitis and airway cough hypersensitivity in chronic non-productive cough. Clin Exp Allergy 2000;30:41-7.

9. Kohno S, Okada K, Kadota J, et al. The Japanese Respiratory Society guidelines for management of cough, second edition, 2012.

10. Niimi A. Geography and cough aetiology. Pulm Pharmacol Ther 2007;20:383-7.

11. Niimi A, Ohbayashi H, Sagara H, et al. Cough variant and cough-predominant asthma are major causes of persistent cough: a multicenter study in Japan. J Asthma
2013;50:932-7.

12. Kanemitsu Y, Kurokawa R, Takeda N, et al. Clinical impact of gastroesophageal reflux disease in patients with subacute/chronic cough. Allergol Int 2019;68:478-85.

13. Dąbrowska M, Grabczak EM, Arcimowicz M, et al. Causes of Chronic Cough in Non-smoking Patients. Adv Exp Med Biol 2015;873:25-33.

14. Takemura M, Niimi A, Matsumoto H, et al. Atopic features of cough variant asthma and classic asthma with wheezing. Clin Exp Allergy 2007;37:1833-9.

15. Tajiri T, Niimi A, Matsumoto H, et al. Prevalence and clinical relevance of allergic rhinitis in patients with classic asthma and cough variant asthma. Respiration 2014;87:211-8.

16. Takemura M, Niimi A, Matsumoto H, et al. Sensitized allergens in cough variant asthma and classic asthma with wheezing. Eur Respir J 2004;24:Suppl 48, (abstract).

17. Jinnai M, Niimi A, Ueda T, et al. Induced sputum concentrations of mucin in patients with asthma and chronic cough. Chest 2010;137:1122-9.

18. Matsumoto H, Niimi A, Takemura M, et al. Features of cough variant asthma and classic asthma during methacholine-induced brochoconstriction: a crosssectional study. Cough 2009;5:3.

19. Niimi A, Fukumitsu K, Takeda N, et al. Interfering with airway nerves in cough associated with asthma. Pulm Pharmacol Ther 2019;59:101854.

20. Asano T, Takemura M, Fukumitsu K, et al. Diagnostic utility of fractional exhaled nitric oxide in prolonged and chronic cough according to atopic status. Allergol Int 2017;66:344-50.

21. Song WJ, Kim HJ, Shim JS, et al. Diagnostic accuracy of fractional exhaled nitric oxide measurement in predicting cough-variant asthma and eosinophilic bronchitis in adults with chronic cough: A systematic review and meta-analysis. J Allergy Clin Immunol 2017;140:701-9.

22. Takeda N, Takemura M, Kanemitsu Y, et al. A preliminary study of novel asthma phenotyping by the predominant site of eosinophilic airway inflammation: Use of dualphased sputum induction. Nagoya Med J 2019;56:107-18.

23. McFadden ER Jr. Exertional dyspnea and cough as preludes to acute attacks of bronchial asthma. N Engl J Med 1975;292:555-9.

24. De Diego A, Martínez E, Perpiñá M, et al. Airway inflammation and cough sensitivity in cough-variant asthma. Allergy 2005;60:1407-11.

25. Niimi A, Torrego A, Nicholson AG, et al. Nature of airway inflammation and remodeling in chronic cough. J Allergy 
Clin Immunol 2005;116:565-70.

26. Niimi A, Matsumoto H, Minakuchi M, et al. Airway remodelling in cough-variant asthma. Lancet 2000;356:564-5.

27. Matsumoto H, Niimi A, Tabuena R, et al. Airway wall thickening in patients with cough variant asthma and nonasthmatic chronic cough. Chest 2007;131:1042-9.

28. Côté A, Russell RJ, Boulet LP, et al. Managing Chronic Cough Due to Asthma and NAEB in Adults and Adolescents: CHEST Guideline and Expert Panel Report. Chest 2020;158:68-96.

29. Takemura M, Niimi A, Matsumoto H et al. Clinical, physiological and anti-inflammatory effect of montelukast in patients with cough variant asthma. Respiration 2012;83:308-15.

30. Niimi A. Cough, asthma, and cysteinyl-leukotrienes. Pulm Pharmacol Ther 2013;26:514-9.

31. Fukumitsu K, Kanemitsu Y, Asano T, et al. Tiotropium attenuates refractory cough and capsaicin cough reflex sensitivity in patients with asthma. J Allergy Clin Immunol Pract 2018;6:1613-1620.e2.

32. Kanemitsu Y, Takakuwa O, Fukumitsu K, et al. Bronchial thermoplasty for severe asthmatic cough. Ann Intern Med 2018;169:61-2.

33. de Marco R, Marcon A, Jarvis D, et al. Prognostic factors of asthma severity: a 9-year international prospective cohort study. J Allergy Clin Immunol 2006;117:1249-56.

34. Çolak Y, Afzal S, Lange P, et al. Role and impact of chronic cough in individuals with asthma from the general population. J Allergy Clin Immunol Pract 2019;7:17831792.e8.

35. Marsden PA, Satia I, Ibrahim B, et al. Objective Cough Frequency, Airway Inflammation, and Disease Control in Asthma. Chest 2016;149:1460-6.

36. Purokivi M, Koskela H, Kontra K. Determinants of asthma control and quality of life in stable asthma: evaluation of two new cough provocation tests. Clin Respir J 2013;7:253-60.

37. Satia I, Tsamandouras N, Holt K, et al. Capsaicinevoked cough responses in asthmatic patients: evidence for airway neuronal dysfunction. J Allergy Clin Immunol 2017;139:771-779.e10.

38. Kanemitsu Y, Fukumitsu K, Kurokawa R, et al. Increased Capsaicin Sensitivity in Patients with Severe Asthma Is Associated with Worse Clinical Outcome. Am J Respir Crit Care Med 2020;201:1068-77.

39. Kanemitsu Y, Matsumoto H, Oguma, T et al. Independent factors contributing to daytime and nighttime asthmatic cough refractory to inhaled corticosteroids. J Investig Allergol Clin Immunol 2019;29:30-9.

40. Fukuhara A, Saito J, Birring SS et al. Clinical Characteristics of Cough Frequency Patterns in Patients with and without Asthma. J Allergy Clin Immunol Pract 2020;8:654-61.

41. Niimi A, Brightling C, Dicpinigaitis PV. Cough in asthma is due to eosinophilic airway inflammation: a pro/con debate. Lung 2014;192:33-8.

42. Teeter JG, Bleecker ER. Relationship between airway obstruction and respiratory symptoms in adult asthmatics. Chest 1998;113:272-7.

43. Brightling CE, Ward R, Goh KL, et al. Eosinophilic bronchitis is an important cause of chronic cough. Am J Respir Crit Care Med 1999;160:406-10.

44. Gibson PG, Zlatic K, Scott J, et al. Chronic cough resembles asthma with IL-5 and granulocytemacrophage colony-stimulating factor gene expression in bronchoalveolar cells. J Allergy Clin Immunol 1998;101:320-6.

45. Brightling CE, Bradding P, Symon FA, et al. Mast cell infiltration of airway smooth muscle in asthma. N Engl J Med 2002;346:1699-705.

46. Siddiqui S, Sutcliffe A, Shikotra A et al. Vascular remodeling is a feature of asthma and nonasthmatic eosinophilic bronchitis. J Allergy Clin Immunol 2007;120:813-9

47. Brightling CE, Symon FA, Birring SS, et al. TH2 cytokine expression in bronchoalveolar lavage fluid T lymphocytes and bronchial submucosa is a feature of asthma and eosinophilic bronchitis. J Allergy Clin Immunol 2002;110:899-905.

48. Brightling CE, Symon FA, Birring SS, et al. Comparison of airway immunopathology of eosinophilic bronchitis and asthma. Thorax 2003;58:528-32.

49. Di Stefano F, Di Giampaolo L, Verna $\mathrm{N}$ et al. Occupational eosinophilic bronchitis in a foundry worker exposed to isocyanate and a baker exposed to flour. Thorax 2007;62:368-70.

50. Brightling CE, Ward R, Wardlaw AJ, et al. Airway inflammation, airway responsiveness and cough before and after inhaled budesonide in patients with eosinophilic bronchitis. Eur Respir J 2000;15:682-6.

51. Birring SS, Parker D, Brightling CE, et al. Induced sputum inflammatory mediator concentrations in chronic cough. Am J Respir Crit Care Med 2004;169:15-9.

52. Park SW, Park JS, Lee YM et al. Differences in radiological/HRCT findings in eosinophilic bronchitis and 
asthma: implication for bronchial responsiveness. Thorax 2006;61:41-7.

53. Ueda T, Niimi A, Matsumoto H, et al. Role of small airways in asthma: Investigation using high-resolution computed tomography. J Allergy Clin Immunol 2006;118:1019-25.

54. Yamaguchi M, Niimi A, Ueda T, et al. Effect of inhaled corticosteroids on small airways in asthma: investigation using impulse oscillometry. Pulm Pharmacol Ther 2009;22:326-32.

55. Asano T, Kanemitsu Y, Takemura M, et al. Small airway inflammation is associated with residual airway hyperresponsiveness in Th2-high asthma. J Asthma 2020;57:933-41.

56. Matsumoto H, Niimi A, Takemura M, et al. Prognosis of cough variant asthma: a retrospective analysis. J Asthma 2006;43:131-5.

57. Fujimura M, Ogawa H, Nishizawa Y, et al. Comparison of atopic cough with cough variant asthma: is atopic cough a precursor of asthma? Thorax 2003;58:14-8.

58. Sun W, Liu HY. Montelukast and Budesonide for Childhood Cough Variant Asthma. J Coll Physicians Surg Pak 2019;29:345-8.

59. Fujimura $M$, Nishizawa $Y$, Nishitsuji $M$ et al. Longitudinal decline in pulmonary function in atopic cough and cough variant asthma. Clin Exp Allergy 2003;33:588-94.

60. Bai TR, Vonk JM, Postma DS et al. Severe exacerbations predict excess lung function decline in asthma. Eur Respir J 2007;30:452-6.

61. Matsuoka H, Niimi A, Matsumoto H, et al. Inflammatory subtypes in cough-variant asthma: association with maintenance doses of inhaled corticosteroids. Chest 2010;138:1418-25.

62. Page SM, Gleich GJ, Roebuck KA, et al. Stimulation of neutrophil interleukin- 8 production by eosinophil granule major basic protein. Am J Respir Cell Mol Biol 1999;21:230-7.

63. Hastie AT, Moore WC, Meyers DA, et al. Analyses of asthma severity phenotypes and inflammatory proteins in subjects stratified by sputum granulocytes. J Allergy Clin Immunol 2010;125:1028-36.e13.

64. Hastie AT, Mauger DT, Denlinger LC, et al. NHLBI SARP 3 Investigators. Baseline sputum eosinophil + neutrophil subgroups' clinical characteristics and longitudinal trajectories for NHLBI Severe Asthma Research Program (SARP 3) cohort. J Allergy Clin Immunol 2020;146:222-6.
65. Brightling CE, Woltmann G, Wardlaw AJ, et al. Development of irreversible airflow obstruction in a patient with eosinophilic bronchitis without asthma. Eur Respir J 1999;14:1228-30.

66. Hancox RJ, Leigh R, Kelly MM, et al. Eosinophilic bronchitis. Lancet 2001;358:1104.

67. Park SW, Lee YM, Jang AS, et al. Development of chronic airway obstruction in patients with eosinophilic bronchitis: a prospective follow-up study. Chest 2004;125:1998-2004.

68. Berry MA, Hargadon B, McKenna S, et al. Observational study of the natural history of eosinophilic bronchitis. Clin Exp Allergy 2005;35:598-601.

69. Lai K, Liu B, Xu D, et al. Will nonasthmatic eosinophilic bronchitis develop into chronic airway obstruction?: a prospective, observational study. Chest 2015;148:887-94.

70. Gibson PG, Hargreave FE, Girbis-Gabardo A, et al. Chronic cough with eosinophilic bronchitis: examination for variable airflow obstruction and response to corticosteroid. Clin Exp Allergy 1995;25:127-32 .

71. Koskela HO, Lätti AM, Purokivi MK. Long-term prognosis of chronic cough: a prospective, observational cohort study. BMC Pulm Med 2017;17:146.

72. Kanemitsu Y, Niimi A, Matsumoto H, et al. Gastroesophageal dysmotility is associated with the impairment of cough-specific quality of life in patients with cough variant asthma. Allergol Int 2016;65:320-6.

73. Irwin RS, Ownbey R, Cagle PT et al. Interpreting the histopathology of chronic cough: a prospective, controlled, comparative study. Chest 2006;130:362-70.

74. Niimi A. Structural changes in the airways: Cause or effect of chronic cough? Pulm Pharmacol Ther 2011;24:328-33.

75. Yousaf N, Montinero W, Birring SS, et al. The long term outcome of patients with unexplained chronic cough. Respir Med 2013;107:408-12.

76. Grainge CL, Lau LC, Ward JA, et al. Effect of bronchoconstriction on airway remodeling in asthma. $\mathrm{N}$ Engl J Med 2011;364:2006-15.

77. Hara J, Fujimura M, Ueda A, et al. Effect of pressure stress applied to the airway on cough-reflex sensitivity in guinea pigs. Am J Respir Crit Care Med 2008;177:585-92.

78. Nakaji H, Niimi A, Matsuoka H, et al. Airway remodeling associated with cough hypersensitivity as a consequence of persistent cough: An experimental study. Respir Investig 2016;54:419-27.

79. Cui S, Ito I, Niimi A, et al. Induction of airway remodeling and persistent cough by repeated citric acid exposure in a guinea pig cough model. Respir Physiol Neurobiol 
2019;263:1-8.

80. Elliot JG, Noble PB, Mauad T, et al. Inflammationdependent and independent airway remodelling in asthma. Respirology 2018;23:1138-45.

81. Niimi A, Chung KF. Evidence for neuropathic processes in chronic cough. Pulm Pharmacol Ther 2015;35:100-4.

82. Global Initiative for Asthma. Global strategy for

Cite this article as: Niimi A. Narrative Review: how long should patients with cough variant asthma or nonasthmatic eosinophilic bronchitis be treated? J Thorac Dis 2021;13(5):3197-3214. doi: 10.21037/jtd-20-2026 asthma management and prevention. Revised version of NHLBI/WHO workshop report: National Institute of Health, 2002.

83. Zhan W, Tang J, Chen X, et al. Duration of treatment with inhaled corticosteroids in nonasthmatic eosinophilic bronchitis: a randomized open label trial. Ther Adv Respir Dis 2019;13:1753466619891520. 